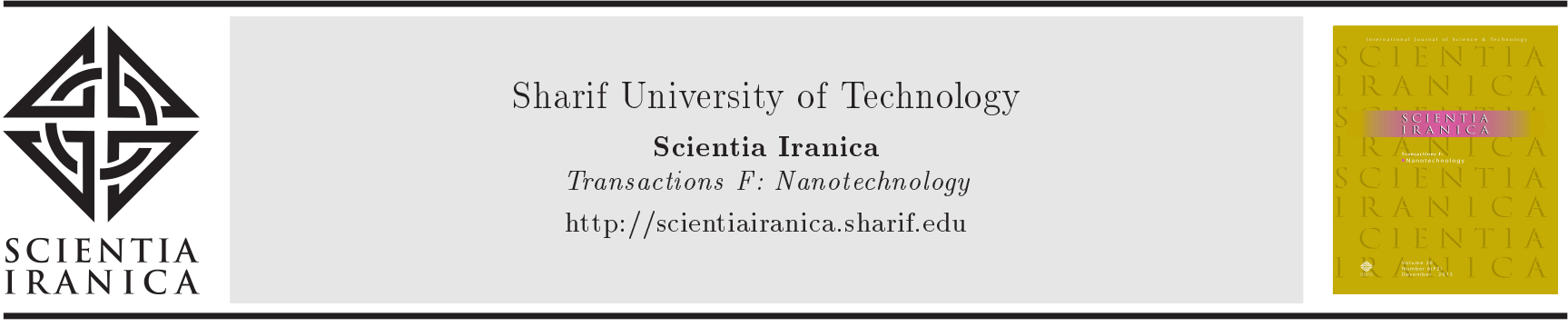

Research Note

\title{
Effect of temperature and time on the structural properties of $\mathrm{PbS}$ nanofilms
}

\author{
F. Akbarbeiglou* \\ Department of Medical Physics, Medical Faculty, Tabriz University of Medical Sciences, Tabriz, Iran.
}

Received 16 October 2017; received in revised form 11 October 2018; accepted 3 December 2018

\section{KEYWORDS}

Lead-sulfide;

Deposition time;

Deposition

temperature;

Atomic force

microscopy;

X-ray diffraction.

\begin{abstract}
In this research, lead acetate as a source of $\mathrm{Pb}^{2+}$ and thiourea as a source of $\mathrm{S}^{2-}$ have been used, and the effects of deposition time $\left(t_{D}<90 \mathrm{~min}\right)$ and deposition temperature $\left(T_{D}: 28,55^{\circ} \mathrm{C}\right)$ on the prepared thin films of Lead-Sulfide have been investigated. In order to investigate the morphology of thin films and crystalline nanostructure of the films, atomic force microscopy and X-ray diffraction have been utilized, respectively. Values of lattice constant for prepared $\mathrm{PbS}$ films vary in the range of $0.5937-$ $0.5959 \mathrm{~nm}$. Preferred growth orientation for prepared films is 200. The thickening process of layers has declined after $60 \min \left(t\right.$ at $28^{\circ} \mathrm{C}: 130-530 \mathrm{~nm}$ and $t$ at $\left.55^{\circ} \mathrm{C}: 300-975 \mathrm{~nm}\right)$.
\end{abstract}

(C) 2019 Sharif University of Technology. All rights reserved.

\section{Introduction}

Nowadays, the technology used for constructing thin films is quite well-known, which has led to the emergence of nanotechnology. Currently, basic properties of nanomaterials are increasingly studied due to their various applications in different fields such as optics. Nanostructured metals are considered as an effective achievement for improving the effectiveness of quantum and functionality of different opto-electronic tools such as solar cells light, emission devices, and photo detectors [1-3].

Thin films are characterized by special properties, and there is a considerable difference in the properties of their related materials in the volumetric mode. This

\footnotetext{
*. Corresponding author. Fax: 041-33364660 E-mail addresses: fakbarbeiglou@yahoo.com and akbarbeiglouf@tbzmed.ac.ir
}

doi: $10.24200 /$ sci. 2018.5381 .1241 difference is created by physical dimensions, geometric shape, and microstructure of the thin films $[4,5]$.

Among different methods of deposition, chemical bath deposition is an easy, quick and cheap method. This method is the most convenient one by which $\mathrm{PbS}$ thin films are prepared. The most important advantages of this method include the possibility of performing deposition on substrates of different kinds, at relatively low temperatures, on substrates with different dimensions, and on a large number of substrates, simultaneously, as well as controllability of effective factors in deposition [6-10].

$\mathrm{PbS}$ is an important chalcogenides semiconductor (IV-VI) with direct narrow gap, an approximate $0.4 \mathrm{eV}$ energy band gap in $300 \mathrm{~K}$, and a great Bohr excitation radius of $18 \mathrm{~nm}$. Narrow band gap and light sensitivity of the above $\mathrm{PbS}$ films in the infrared range have made these films useful elements for electro-optics, sensors, and engineering. $\mathrm{PbS}$ is used in optical resistance, fire detectors, fire alarm systems, diode lasers, night vision instruments, temperature and moisture sensors, solar cells, and decorative coatings [11-16]. 
This study investigates the effect of deposition time $\left(t_{D}<90 \mathrm{~min}\right)$ and deposition temperature $\left(T_{D}\right.$ : $28,55^{\circ} \mathrm{C}$ ) on the morphology and structure of $\mathrm{PbS}$ nanofilms deposited by the chemical bath method.

\section{Methods}

In this research work, glass substrates with dimensions of $25.4 \times 76.2 \times 1.2 \mathrm{~mm}$ were used for deposition. One of the most important points that deserves much attention is cleanliness of the substrates, since it has a direct relationship with the degree of film-to-substrate viscosity, leading to a clean film. Accordingly, 8 glass substrates were washed with detergent liquid, alcohol, acetone, and finally distilled water. For Lead-sulfide deposition, lead acetate and thiourea as preparation sources of $\mathrm{Pb}^{2+}$ and $\mathrm{S}^{2-}$ were used, respectively. Then, $50 \mathrm{ml}$ of $0.1 \mathrm{M}$ lead acetate solution and $50 \mathrm{ml}$ of $0.1 \mathrm{M}$ thiourea solution were mixed together and, by adding distilled water, the solution volume rate reached 150 $\mathrm{ml}$. Then, by using ammonia, the $\mathrm{pH}$ rate of the solution was set to 10 . In order to prepare films, 4 substrates at a temperature of $28^{\circ} \mathrm{C}$ and, also, 4 others at a temperature of $55^{\circ} \mathrm{C}$ were plunged perpendicularly. Deposition time was considered 20,40,60, and 80 minutes, respectively. Chemical steps of Lead sulfide preparation are as follows:

$$
\begin{aligned}
& \mathrm{Pb}\left(\mathrm{CH}_{3} \mathrm{COO}\right)_{2} \leftrightarrow \mathrm{Pb}^{2+}+2\left(\mathrm{CH}_{3} \mathrm{COO}\right)^{-} \\
& \mathrm{NH}_{3}+\mathrm{H}_{2} \mathrm{O} \leftrightarrow \mathrm{NH}_{4}+\mathrm{OH}^{-} \\
& \mathrm{CH}_{2} \mathrm{~N}_{2}+\mathrm{H}_{2} \mathrm{O}+\mathrm{HS}^{-} \leftrightarrow\left[\left(\mathrm{H}_{2} \mathrm{~N}\right)_{2} \mathrm{CS}\right]+\mathrm{OH}^{-} \\
& \mathrm{HS}^{-}+\mathrm{OH}^{-} \leftrightarrow \mathrm{H}_{2} \mathrm{O}+\mathrm{S}^{2-} \\
& \mathrm{Pb}^{2+}+\mathrm{S}^{2-} \leftrightarrow \mathrm{PbS}
\end{aligned}
$$

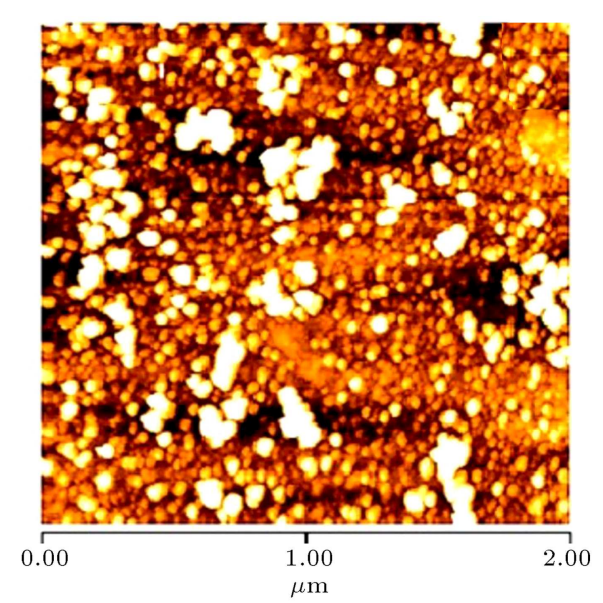

(a)
The surface morphology of thin films has been studied by Atomic Force Microscopy (AFM) and nanostructure of thin films by using X-Ray Diffraction (XRD) method, and the relationship between time and temperature deposition has been considered by the nanostructure of the films.

\section{Results and discussion}

Figure 1(a) and (b), respectively, show the AFMobtained two-dimensional images related to the constructed lead-sulfide sample at room temperature $\left(28^{\circ} \mathrm{C}\right)$ and deposition times of 20 and $80 \mathrm{~min}$.

Figure 2(a) and (b), respectively, show the AFMobtained two-dimensional images of the constructed lead-sulfide nanocrystalline film at a deposition temperature of $55^{\circ} \mathrm{C}$ and deposition times of 20 and 80 $\min$.

The prepared film at room temperature and a deposition time of $20 \mathrm{~min}$ is full of lead-sulfide small grains and, by increasing deposition time to 80 minutes at the same room temperature, the surface will be full of huge clusters (holes are regions with black color in the images and grains are white color points). Huge clusters that have been deposited on the surface of the film at $55^{\circ} \mathrm{C}$ clearly show an impact structure in comparison with the film prepared with the same deposition time, yet with room temperature deposition. The results are in agreement with those obtained by Abbas et al. [3] and Aadim et al. [6].

Figure 3(a) and (b), respectively, indicate the AFM-obtained three-dimensional images related to deposited lead-sulfide samples at a deposition temperature of $28^{\circ} \mathrm{C}$ and different deposition times of 20 and $80 \mathrm{~min}$.

Figures 4 (4a) and (4b), respectively, represent the AFM-obtained three-dimensional images of the

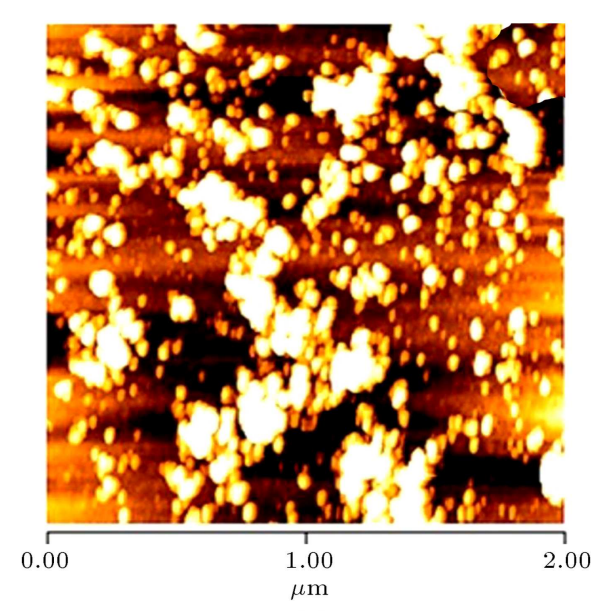

(b)

Figure 1. Two-dimensional images of AFM for deposited thin PbS films at $28^{\circ} \mathrm{C}$ and deposition times of (a) 20 min and (b) 80 min. 


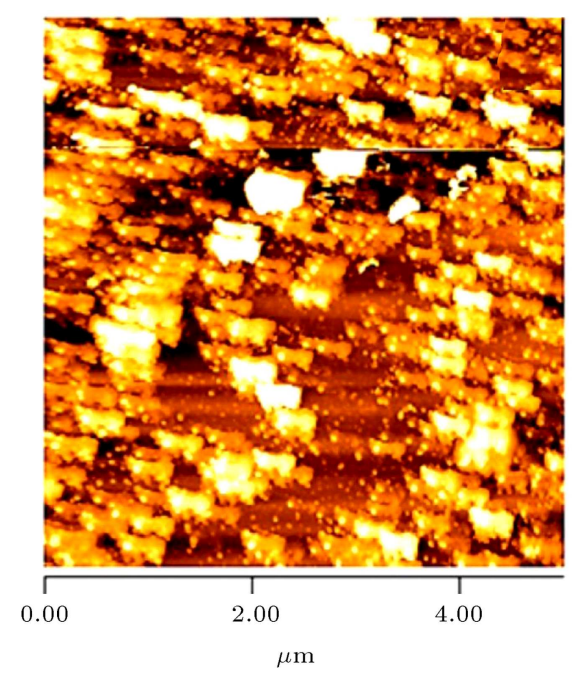

(a)

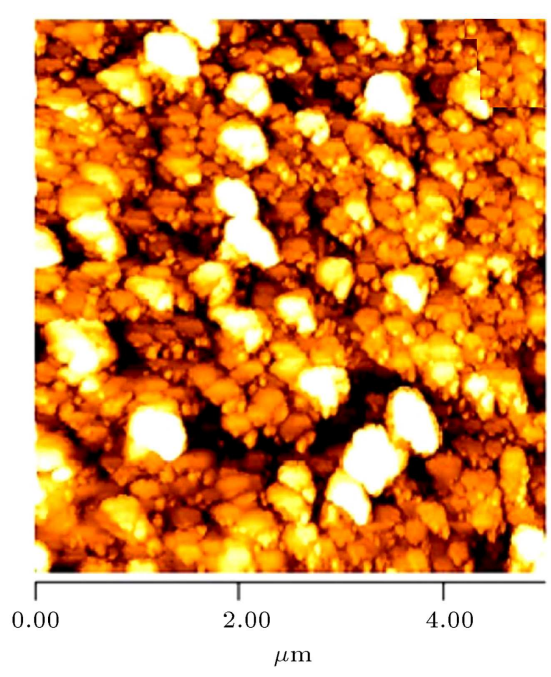

(b)

Figure 2. Two-dimensional images of AFM for deposited thin $\mathrm{PbS}$ films at $55^{\circ} \mathrm{C}$ and deposition times of (a) 20 min and (b) $80 \mathrm{~min}$.

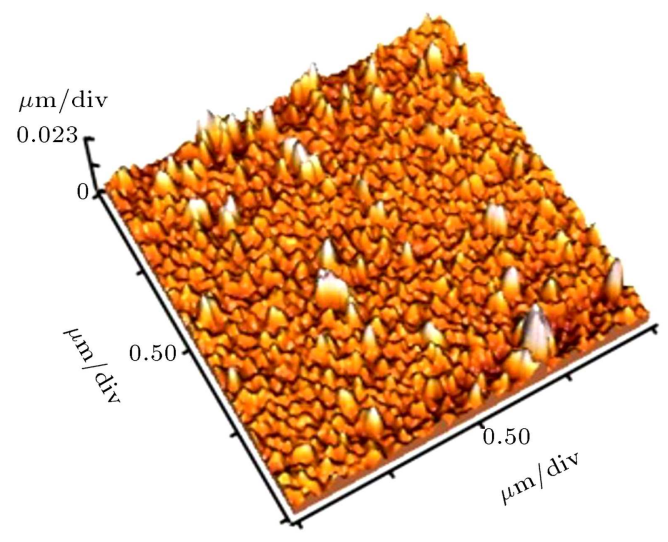

(a)

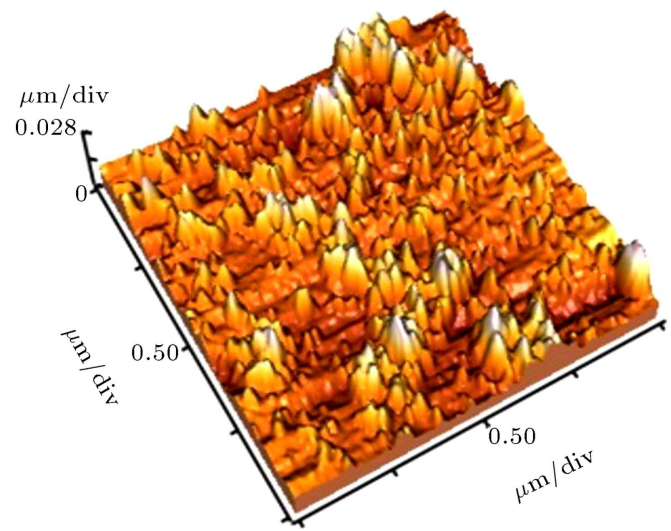

(b)

Figure 3. Three-dimensional images of AFM for deposited thin $\mathrm{PbS}$ films at $28^{\circ} \mathrm{C}$ and deposition times of (a) 20 min and (b) $80 \mathrm{~min}$.

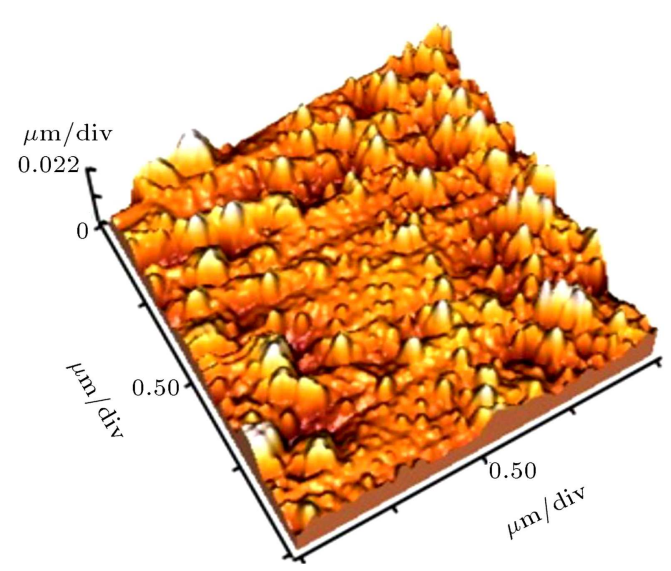

(a)

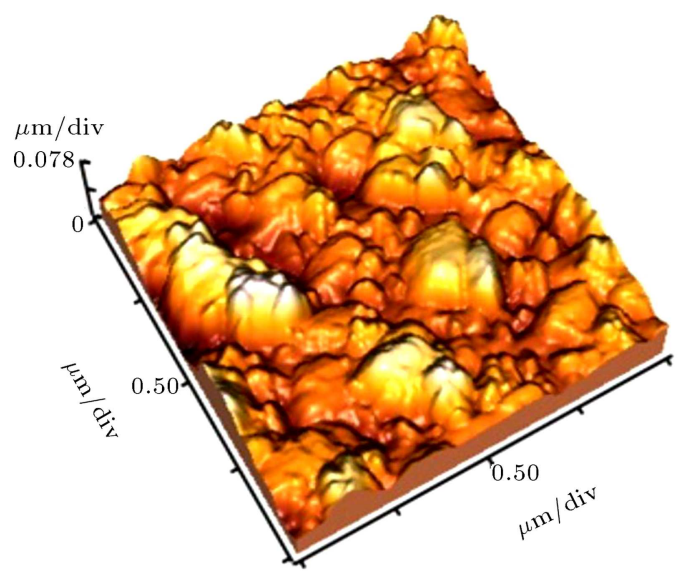

(b)

Figure 4. Three-dimensional images of AFM for deposited thin $\mathrm{PbS}$ films at $55^{\circ} \mathrm{C}$ and deposition times of (a) 20 min and (b) $80 \mathrm{~min}$. 


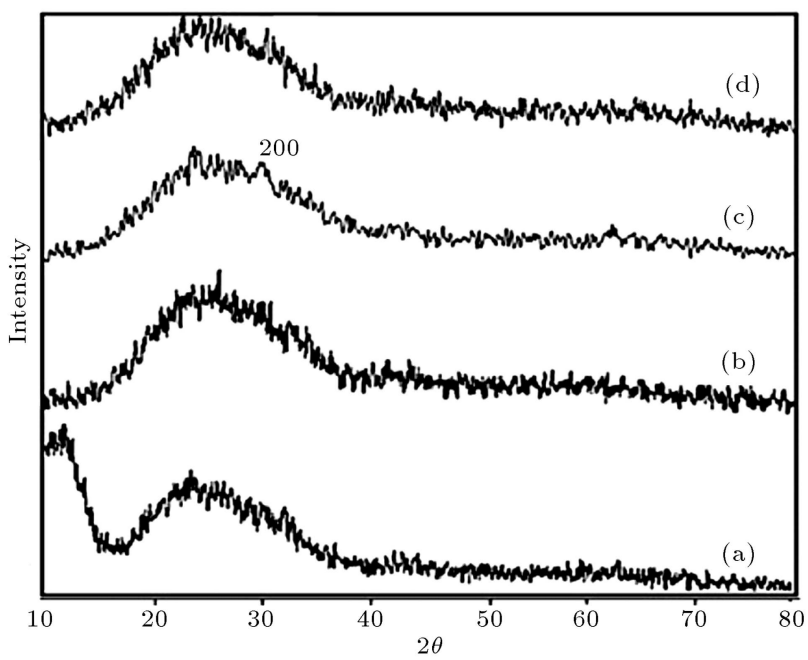

Figure 5. X-ray diffraction patterns of thin $\mathrm{PbS}$ films prepared at a temperature of $28^{\circ} \mathrm{C}$ and deposition times of (a) $20 \mathrm{~min}$, (b) $40 \mathrm{~min}$, (c) $60 \mathrm{~min}$, and (d) $80 \mathrm{~min}$.

constructed lead-sulfide nanocrystalline film at a deposition temperature of $55^{\circ} \mathrm{C}$ and deposition times of 20 and $80 \mathrm{~min}$.

Based on the comparison of Figures 3 and 4, it is obviously seen that temperature enhances kinetic energy and activation energy of the grains.

Obtained changes derived from deposition temperature in the structural properties and surface morphology of the $\mathrm{PbS}$ films can be linked to the enhancement of $\mathrm{S}^{2-}$ and $\mathrm{Pb}^{2+}$ ions in reaction solution at higher temperatures. Enhancement of metal ions is a thermal creation process; in addition, thiourea, which is a source of $\mathrm{S}^{2-}$ ions reaction, is more active at higher temperatures.

Figure 5 shows diagrams of X-ray diffraction for the constructed $\mathrm{PbS} /$ glass films at room temperature and in of $20,40,60$, and 80 minutes, respectively.

Diagrams are quite crowded due to amorphous glass substrates, and a wide peak is observed at an angle of $20^{\circ}$ to $30^{\circ}$, which is related to the glass substrate.

As is seen, constructed films in 20 and 40 minutes are completely amorphous and, by increasing deposition time and enhancing film thickness, a crystalline peak with an approximate value of $2 \theta: 30$ appears in the sample at a deposition time of $60 \mathrm{~min}$. However, thickness of the prepared film at $80 \mathrm{~min}$ decreases.

The reason for this behavior originates from the fact that forming ions $\left(\mathrm{Pb}^{2+}, \mathrm{S}^{2-}\right)$ in the reaction bath through the further enhancement of deposition time decrease and get low gradually as a result of enhancement of time thickness of the films.

Figure 6 displays X-ray diffraction diagrams of deposited lead-sulfide samples on a glass substrate at a deposition temperature of $55^{\circ} \mathrm{C}$ and deposition times of $20,40,60$, and 80 minutes, respectively.

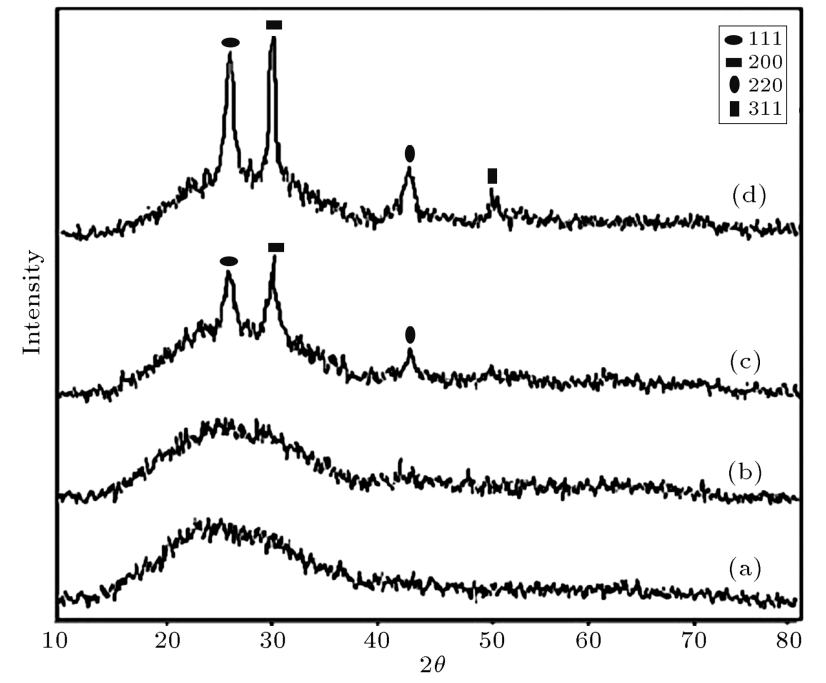

Figure 6. X-ray diffraction patterns of thin $\mathrm{PbS}$ films prepared at a temperature of $55^{\circ} \mathrm{C}$ and deposition times of (a) $20 \mathrm{~min}$, (b) $40 \mathrm{~min}$, (c) $60 \mathrm{~min}$ and (d) $80 \mathrm{~min}$.

Figure 6 (a) and (b) show the constructed samples in a shorter deposition time, i.e., 20 and 40 minutes. Similar to the formed films at room temperature, the constructed samples have become amorphous at the same time with no sign of a peak regarding $\mathrm{PbS}$.

Diffraction patterns show 4 peaks with approximate values of $2 \theta=26,30,43$, and 51 that enjoy compatibility with obtained diffraction lines by crystalline planes of cubic phase of lead-sulfide, i.e., (111), (200), (220), and (311), respectively. It is observed that there is one preferred growth orientation along the (200) plane, and it is in agreement with the results obtained by Faraj et al. [8] and Pineda et al. [9].

Diagrams of XRD are representative of this point, such that when the deposition temperature increases, grains may have complete orientation and crystalline peaks can appear to be higher with higher intensity.

Concerning the prepared films at a temperature of $55^{\circ} \mathrm{C}$, by increasing the solution temperature, complex decomposition and thiourea increase. Enhancement of ions density and the kinetic energy leads to further reaction between ions and, consequently, will enhance the thickness of the films.

Figure 7 (a) and (b) indicate diagrams of thickness changes due to the enhancement of deposition time at temperatures of $28^{\circ} \mathrm{C}$ and $55^{\circ} \mathrm{C}$, respectively $(t=$ $m / \rho A$, where $m$ is the film mass, $\rho$ is the film density, and $A$ is the film surface area). These results are in agreement with Ezekoye et al. reports [2].

In Table 1, values of $d$ (distance between the planes), have been calculated and compared with those reported in ASTM information file. It is seen that values of $d$ are favorably compatible with ASTM standard values.

Table 2 shows values of lattice constant related to 


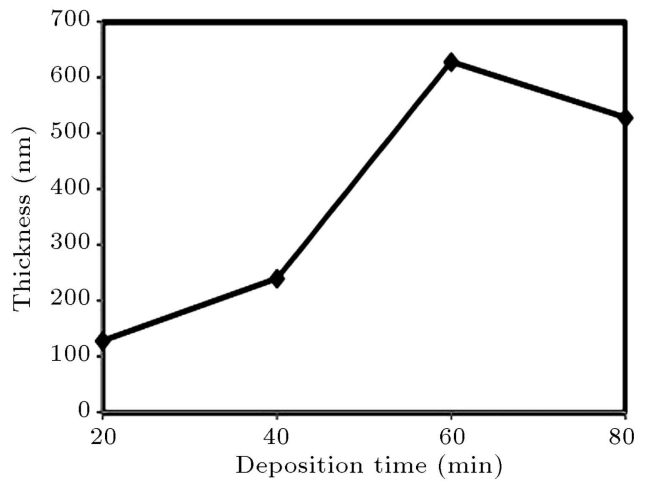

(a)

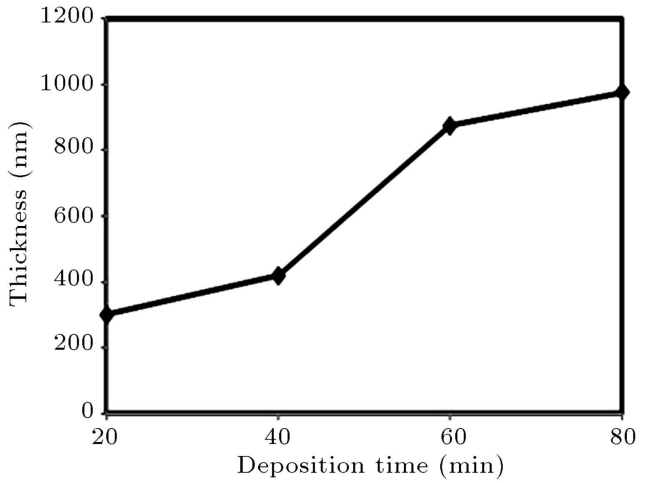

(b)

Figure 7. Variations of film thickness with deposition time for the prepared thin $\mathrm{PbS}$ films at temperatures of $(\mathrm{a}) 28^{\circ} \mathrm{C}$ and (b) $55^{\circ} \mathrm{C}$.

Table 1. Comparison of the observed $d$-values for PbS with the ASTM standard.

\begin{tabular}{|c|c|c|c|c|c|}
\hline \multirow[t]{2}{*}{ hkl } & \multirow[t]{2}{*}{$2 \theta$ (deg.) } & \multicolumn{4}{|c|}{$d(\mathrm{~nm})$} \\
\hline & & c layer $\left(28^{\circ} \mathrm{C}\right)$ & c layer $\left(55^{\circ} \mathrm{C}\right)$ & d layer $\left(55^{\circ} \mathrm{C}\right)$ & standard \\
\hline 111 & 26 & - & 0.3454 & 0.3433 & 0.3429 \\
\hline 200 & 30 & 0.2977 & 0.2956 & 0.2972 & 0.2969 \\
\hline 220 & 43 & - & 0.2094 & 0.2111 & 0.2099 \\
\hline 311 & 51 & - & - & 0.1802 & 0.1790 \\
\hline
\end{tabular}

Table 2. Lattice constant values for $\mathrm{PbS}$ thin films.

\begin{tabular}{cc}
\hline Thin film & $\begin{array}{c}\text { Lattice constant }(\mathbf{n m}) \\
\boldsymbol{a}=\boldsymbol{d}\left(\boldsymbol{h}^{\mathbf{2}}+\boldsymbol{k}^{\mathbf{2}}+\boldsymbol{l}^{\mathbf{2}}\right)^{\mathbf{1 / 2}}\end{array}$ \\
\hline c $\left(28^{\circ} \mathrm{C}\right)$ & 0.5954 \\
$\mathrm{c}\left(55^{\circ} \mathrm{C}\right)$ & 0.5937 \\
$\mathrm{~d}\left(55^{\circ} \mathrm{C}\right)$ & 0.5959 \\
\hline
\end{tabular}

nanofilms. The values shown in Tables 1 and 2 are in good agreement with those of other reports [3,4].

Considering the prepared films at different times and temperatures, it can be concluded that time and temperature are the deposition conditions that strongly affect the film's stoichiometry, microstructure, and crystallinity.

\section{Conclusion}

The results obtained from XRD and AFM demonstrate that, at both deposition temperatures, the layers with higher thickness enjoy a better crystalline structure (layer $\mathrm{C}$ at $28^{\circ} \mathrm{C}$ has 1 crystalline peak, layer $\mathrm{C}$ at $55^{\circ} \mathrm{C}$ has 3 crystalline peaks, and layer $\mathrm{D}$ at $55^{\circ} \mathrm{C}$ has 4 crystalline peaks) With respect to the obtained results of the prepared films at a temperature of $55^{\circ} \mathrm{C}$ such as the deposited films at room temperature, the thickness change trend was observed with deposition time, yet with minor differences resulting from temperature effects on the reaction bath. The general rule of a nonlinear relation that exists between deposition time and thickness values at a specified time interval is not obvious in this project. However, certainly, by increasing the deposition time interval for the prepared films at a temperature of $55^{\circ} \mathrm{C}$, a similar behavior of the obtained films at a temperature of $28^{\circ} \mathrm{C}$ was observed (reduction of the thickness progression after $60 \mathrm{~min}: t$ $\left(28^{\circ} \mathrm{C}\right): 130,240,630,530 \mathrm{~nm}$ and $t\left(55^{\circ} \mathrm{C}\right): 300,420$, $875,975 \mathrm{~nm})$.

\section{References}

1. Govindasamy, G., Murugasen, P., and Sagadevan, S. "Optical and electrical properties of chemical bath deposited cobalt sulphide thin films", J. Mater. Res., 20(1), pp. 62-67 (2017).

2. Ezekoye, B., Emeakaroha, T., and Ezekoye, V. "Optical and structural properties of lead sulphide $(\mathrm{PbS})$ thin films synthesized by chemical method", Int. J. Phys. Sci., 10(13), pp. 385-390 (2015).

3. Abbas, M., Shehab, AA-M., and Al-Samuraee, A. "Effect of deposition time on the optical characteristics of chemically deposited nanostructure PbS thin films", Energy Procedia, 6, pp. 241-250 (2011).

4. Göde, F., Güneri, E., and Emen, F. "Synthesis, structural, optical, electrical and thermoluminescence properties of chemically deposited PbS thin films", $J$. Lumin., 147, pp. 41-48 (2014).

5. Choudhury, N. and Sarma, B. "Structural characterization of nanocrystalline $\mathrm{PbS}$ thin films synthesized by CBD method", Indian J. Pure Appl. Phys., 46, pp. 261-265 (2008). 
6. Aadim, K.A., Ibrahim, A-ME., and Marie, J.M. "Structural and optical properties of $\mathrm{PbS}$ thin films deposited by pulsed laser deposited (PLD) technique at different annealing temperature", Int. J. Phys., 5(1), pp. 1-8 (2017).

7. Preetha, K. "Structural, electronic transport and optical properties of $\mathrm{Cr}$ doped $\mathrm{PbS}$ thin film by chemical bath deposition", AIP Conf. Proc, India, 1849(1), p. 020018 (2017).

8. Faraj, M.G. and Omar, H.D. "The effect of substrate temperature on the structural properties of spray pyrolysed lead sulphide $(\mathrm{PbS})$ thin films", ARO Sci. J. Koya U, 2(2), pp. 11-14 (2016).

9. Pineda-Leon, H., Gutierrez-Heredia, G., and De Leon, A. "Comparative study of $\mathrm{PbS}$ thin films growth by two different formulations using chemical bath deposition", Chalcogenide Lett., 13(4), pp. 161-168 (2016).

10. Ruiz-Preciado, L., Quevedo-Lopez, M., and RojasHernandez, A. "Study of the growth of $\mathrm{PbS}$ thin films on common glass, Hfo2/Si and Sio2/Si substrates, prepared by CBD", Dig J Nanomater Bios, 11(4), pp. 1205-1211 (2016).

11. Akhmedov, O., Guseinaliyev, M., and Abdullaev, N. "Optical properties of PbS thin films", Semiconductors, 50(1), pp. 50-53 (2016).

12. Obaid, A., Mahdi, M., and Hassan, Z. "Characterization of nanocrystalline $\mathrm{PbS}$ thin films prepared using microwave-assisted chemical bath deposition", Mat Sci Semicon Proc, 15(5), pp. 564-571 (2012).

13. Sengupta, S., Perez, M., and Rabkin, A. "In situ monitoring the role of citrate in chemical bath deposition of PbS thin films", Cryst. Eng. Comm., 18(1), pp. 149156 (2016).

14. Song, C., Sun, M., and Yin, Y. "Synthesis of starshaped lead sulfide (PbS) nanomaterials and theirs gas-sensing properties", J. Mater. Res., 19(6), pp. 1351-1355 (2016).

15. Afshar, A. "Anodizing of Titanium in $\mathrm{NaOH}$ solution and its corrosion resistance in PBS physiologic solution", Scientia Iranica, 10(3), pp. 361-366 (2003).

16. Ho, S.-M., Kassim, A., Abdullah, A.-H., and Nagalingam, S. "XRD, AFM and UV-Vis optical studies of PbSe thin films produced by chemical bath deposition method", Scientia Iranica, 17(2), pp. 139-143 (2010).

\section{Biography}

Fatemeh Akbarbeiglou, MSc, is a Lab. Officer at the Department of Medical Physics at College of Medicine, Tabriz University of Medical Sciences. She received BS and MSc degrees in Physics from University of Urmia in 2009 and 2012, respectively. Her research interests include thin film, nano layers, and nano technology. 